\title{
A case of allergic contact dermatitis due to application of synthetic casting which mimics the manifestation of cellulitis
}

\author{
Tülin Türközü and Necip Güven \\ Republic of Turkey Ministry of Health, Health Sciences University, Van Education and Research Hospital Department \\ of Trauma and Orthopedic Surgery, Van, Turkey
}

\begin{abstract}
Casting application is one of the essential aspects with respect to conservative treatment of fractures in Orthopaedics and it may be applied after surgical treatment when needed. In the recent years, common use of synthetic cast (45\% polyurethane resin and 55\% fiberglass) and also undercast cotton padding (synthetic fiber) caused an increased incidence of allergic contact dermatitis. It may develop an allergic reaction progressing accompanied by eruptions and itching as commonly experienced in our daily orthopaedic practice. We have presented a case of allergic contact dermatitis which mimics an unusual manifestation of cellulitis in routine clinical practice.
\end{abstract}

Key Words: Synthetic cast, Allergic contact dermatitis, cellulitis, mimic

\section{Introduction}

Allergic contact dermatitis is an allergic or inflammatory skin reaction that may occur due to contact effect with external foreign substances. Acute phase is characterized by erythematous, scaly plaques. In severe cases vesiculation and bullae in exposed areas are very characteristic.

Cellulitis is a common bacterial skin infection. Cellulitis may first appear as a red, swollen area that feels hot and tender to the touch. The redness and swelling often spread rapidly. Cellulitis is usually painful.

\section{Case report}

The 27-year-old male patient admitted to the orthopaedic outpatients department due to sprain the complaint of ankle. The patient has swelling, diffuse ecchymosis and increased sensitivity in the circumference of left lateral malleolus. The performed radiography revealed nondisplaced fracture in the lateral malleolus. No pathology was found in the examination of syndesmosis. Conservative treatment was planned for the fracture and a synthetic short leg cast was applied. The patient was recommended immobilization for about 45 days using a crutch, without putting on weight on the broken foot. The patient was performed limb elevation because of the risk for compartment syndrome and he was initiated Clexane 0.6 sc $1 \times 1$ for prophylaxis of deep venous thrombosis. The patient who had interdigital tinea pedis was recommended to visit the Dermatology Outpatients Department and dated due to visit the Orthopaedic Outpatients Department one week later for control examination.

The patient readmitted to our outpatient department due to the complaint of intolerable sensation of burning and pain 4 days later. It was determined that no swelling of the fingers and painful finger movement was present. The short leg cast of the patient was replaced with a splint and ankle circumference was evaluated. There was diffuse swelling, edema, redness and increased temperature in his ankle and especially around lateral malleolus (Figure 1). In accordance with the findings of the physical examination, the patient was admitted in the ward due to prediagnosis of cellulitis. Test of the infection markers was ordered and antibiotic treatment was initiated. A consultation of Department of Dermatology was ordered because of tinea pedis and the treatment regime recommended by Department of Dermatology was initiated. Extremity elevation was ordered while wet and cold dressing was started. Of the whole blood and infections tested in the first admission day; WBC: $9.9 \mathrm{~K} / \mathrm{mcL}$, 
GRAN: $7.7 \mathrm{~K} / \mathrm{mcL}$, LYM: $1.7 \mathrm{~K} / \mathrm{mcL}$, CRP: 20 $\mathrm{mg} / \mathrm{L}$, SED: $13 \mathrm{~mm} /$ hour. In the second admission day, no change was encountered in the physical findings of his ankle however cold and wet dressing reduced the sensation of burning. The whole blood and infection markers in the third admission day was measured such as WBC: $7.3 \mathrm{~K} / \mathrm{mcL}$, GRAN: $5.5 \mathrm{~K} / \mathrm{mcL}$, LYM: 1.4 $\mathrm{K} / \mathrm{mcL}$, CRP: $42.3 \mathrm{mg} / \mathrm{L}$ and SED: $47 \mathrm{~mm} /$ hour. In the 4th admission day; since no change was monitored in the swelling, edema and redness in the ankle and also the marker tests resulted: WBC: $8.7 \mathrm{~K} / \mathrm{mcL}$, GRAN: $7.7 \mathrm{~K} / \mathrm{mcL}$, LYM: 0.7 $\mathrm{K} / \mathrm{mcL}$, CRP: $39 \mathrm{mg} / \mathrm{L}$ and SED: $51 \mathrm{~mm} /$ hour; it was considered that the lesion around lateral malleolus may be allergic contact dermatitis due to use of synthetic cast and under cast cotton therefore a consultation by the Department of Dermatology was reordered. The steroid and antihistaminic treatment initiated in the 4th admission day provided a dramatic improvement in the clinical condition of the patient in the 5 th admission day (Figure 2). Whole blood and infection markers were measured as WBC: 12.1 $\mathrm{K} / \mathrm{mcL}$, GRAN: $10.6 \mathrm{~K} / \mathrm{mcL}$, LYM: $1.1 \mathrm{~K} / \mathrm{mcL}$, CRP: $17.7 \mathrm{mg} / \mathrm{L}$ and SED: $57 \mathrm{~mm} /$ hour. The slightly increased leukocytosis was considered associated with administration of steroids. In the 6th admission day; whole blood and infection markers were measured as WBC: $10.1 \mathrm{~K} / \mathrm{mcL}$, GRAN: $8.2 \mathrm{~K} / \mathrm{mcL}$, LYM: $1.4 \mathrm{~K} / \mathrm{mcL}$, CRP: 6.3 $\mathrm{mg} / \mathrm{L}$ and SED: $48 \mathrm{~mm} /$ hour. The clinical picture of the patient was improved and the patient was discharged and dated for a control examination one week later.

At the control examination in the polyclinic one week later; the physical condition of ankle was found completely recovered. Whole blood and infection markers were measured as WBC: 11.2 $\mathrm{K} / \mathrm{mcL}$, GRAN: $7.9 \mathrm{~K} / \mathrm{mcL}$, LYM: $2.6 \mathrm{~K} / \mathrm{mcL}$, CRP: $3.5 \mathrm{mg} / \mathrm{L}$ and SED: $14 \mathrm{~mm} /$ hour and fracture in his ankle was applied 100\% cotton under cast stocking and followed-up by application of splint.

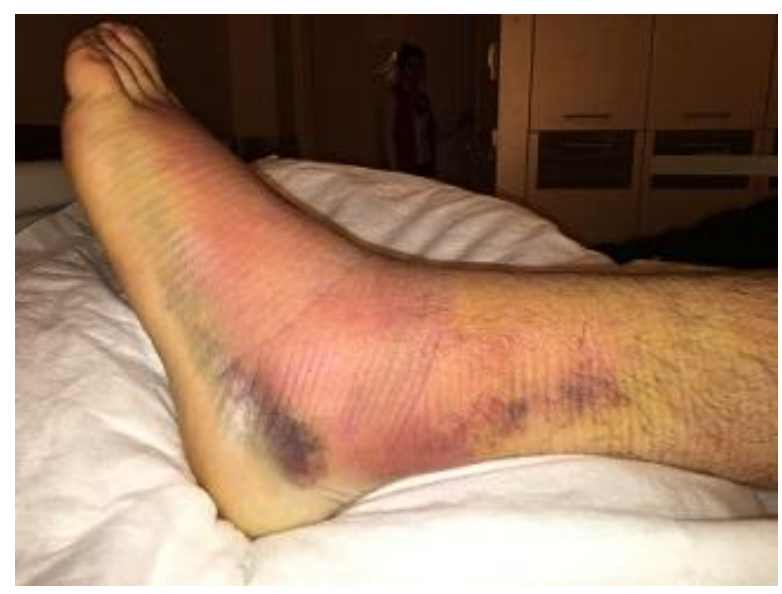

Fig. 1. The appearance of patient's ankle after removal of the synthetic cast.

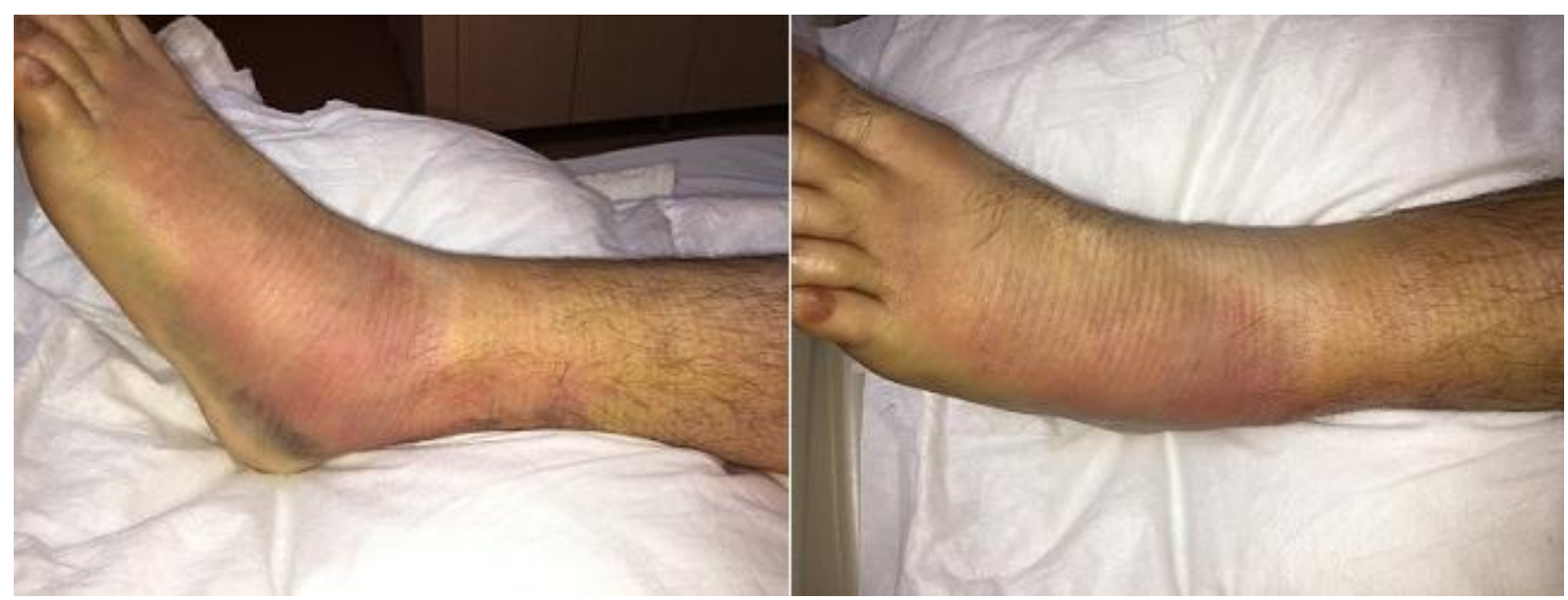

Fig. 2. The appearance of the ankle after steroid and antihistaminic treatment.

East J Med Volume:22, Number:4, October-December/2017 


\section{Discussion}

The most common complication associated with casting application is pressure or friction injuries. Beside these, other complications may include compartment syndrome, thermal injuires and skin infection. Long-term use of a casting may cause more severe complications such as chronic pain, joint stiffness, muscular atrophy, complex regional pain syndrome or venous thrombosis and further pulmonary embolism $(1,2,3)$.

Allergic contact dermatitis is an itchy dermatitis condition. The clinical picture may vary depending upon strength of allergen, contact duration, reaction site and sensitivity degree of the subject (4-9). In the acute period; erythematous macule, papules, vesicles and bullae may be monitored. Lesions have regular margins and are localized at the contact site. Dilution may decrease in one or two weeks. In the subacute period, vesicles change to crusts, desquamation is remarkable. It may become chronic if contact with the allergen proceeds or the allergen is not removed. In the chronic term; completely dry skin, thickening of the skin, lichenification and fissures form $(4,7,9)$.

Allergic contact dermatitis secondary to casting application is commonly observed in the daily orthopaedic practice. There is a limited number of studies on this subject in the literature. In this case; absence of leukocytosis in the laboratory test results corroborated the conclusion that the present condition may be due to allergic contact dermatitis secondary to use of sythetic cast or under cast cotton although the clinical findings of the patient were exactly compatible with cellulitis. After dramatically positive response of the patient to steroid treatment and absence of leukocytosis, a definite diagnosis of allergic contact dermatitis could be established. In this case of allergic contact dermatitis, present clinical symptoms were different from the general findings and mimicked cellulitis. The clinical picture of cellulitis should be certainly supporeted by the laboratory results. It should be also beard in mind that allergic contact dermatitis may develop resulting from the use of synthetic casting and undercast cotton padding.

\section{References}

1. Halanski M, Noonan KJ. Cast and splint immobilization: complications. J Am Acad Orthop Surg 2008; 16: 30-40.

2. Clarke AM, Winson IG. Does plaster immobilization predispose to pulmonary embolism? Injury 1992; 23: 533-534.

3. Halanski MA, Halanski AD, et al. Thermal injury with contemporary cast-application techniques and methods to circumvent morbidity. J Bone Joint Surg Am 2007; 89: 2369-2377.

4. Belsito DV. Allergic Contact Dermatitis. In: Fitzpatrick TB, Fredberg TM, Eisen AZ, Wolff K, Austen FK, Goldsmith LA, Katz S editors. Dermatology in General Medicine, 5th ed. New York: Mc Graw Hill 1999; p. 1447-1461.

5. Marks JG, Elsner P, Deleo VA. Contact\&Occupational Dermatology. 3rd ed. St. Louis: Mosby 2002; p.3-15.

6. Krasteva M, Kehren J, Sayag M, et al. Contact dermatitis II. Clinical aspects and diagnosis. Eur J Dermatol 1999; 9: 144-159.

7. Kadyk Dl, McCarter K, Achen F, Belsito DV. Quality of life in patients with allergic contact dermatitis. J Am Acad Dermatol 2003; 49: 1037 1048.

8. Li LY, Cruz PD. Allergic contact dermatitis: pathophysiology applied to future therapy. Dermatologic Therapy 2004; 17: 219-223.

9. Aydemir EH. Allergic contact dermatitis. Türkiye Klinikleri 2005; 1: 19-21. 